\title{
Severe herpes zoster ophthalmicus in young African adults: a marker for HTLV-III seropositivity
}

\author{
P KESTELYN, A M STEVENS, E BAKKERS, D ROUVROY, \\ AND P VAN DE PERRE \\ From the Centre Hospitalier de Kigali, Rwanda
}

SUMMARY This report proves the relationship between herpes zoster ophthalmicus and seropositivity for HTLV-III in young and often apparently healthy African patients. The ophthalmologist should screen patients with herpes zoster ophthalmicus for antibodies against HTLV-III in areas where this virus is endemic or if the patient belongs to a known risk group. If the test is positive, the patient should be instructed about the infectious nature of his condition to prevent spread of this sexually transmitted disease. As the rate of corneal involvement and postherpetic neuralgia are very high in these patients, it would be worthwhile to ascertain whether routine use of acyclovir treatment in HTLV-III seropositive patients with herpes zoster has a beneficial effect on these complications.

It is well known that herpes zoster infections occur with greater frequency in immunocompromised patients.' Since the first description of HTLV-III infection in Rwanda in $1984,{ }^{2}$ the number of cases of herpes zoster ophthalmicus (HZO) seen in our ophthalmology department at the Centre Hospitalier de Kigali has been steadily increasing. The purpose of the present study was twofold. First we wanted to determine whether there is a relationship between this increasing frequency of $\mathrm{HZO}$ and the presence of HTLV-III in the population. Secondly we wanted to document the degree of eye damage caused by this herpetic infection.

\section{Material and methods}

All patients with HZO followed up in our department between September 1985 and February 1986 were tested for antibodies against HTLV-III with a commercial ELISA kit (Vironostica Organon Teknika BV Boxtel Holland), as recommended by the World Health Organisation (Bangui Conference, 22-23 October 1985). Positive tests were confirmed by an indirect immunofluorescence method using HTLV-III infected $\mathrm{H} 9$ fixed cells and uninfected H9 cells as an internal control. ${ }^{3}$ In addition to the routine ocular examination, including visual acuity testing, slit-lamp examination, and funduscopy, a standard

Correspondence to Dr P Kestelyn, ICEPO Room 120, Wilmer Institute, 600 North Wolfe Street, Baltimore, MD 21205, USA. questionnaire was completed giving information about the patient's geographic origin (prefecture), his residency (urban versus rural), first date of diagnosis, involvement of one or more dermatomes, duration of the healing period, and presence or absence of postzonal neuralgia. Whenever possible the patients were examined at weekly intervals until healing or stabilisation of their infection took place. HTLV-III antibodies were also determined in a control group matched for age, sex, geographic origin, and residency. This control group was recruited from healthy blood donors; three controls were taken for each patient with HZO.

\section{Results}

In this five-month period we diagnosed 19 cases of HZO in 15 male and four female patients. In 17 patients a typical skin eruption was present on the nose (nasociliary nerve) and on the forehead (frontal nerve). In two patients (cases 12 and 19) the eruption was mainly located on the cheek (branches of the maxillary division of the fifth nerve), but there was mild involvement of the frontal and nasociliary nerves as well. Although the skin lesions were often deep and healed with conspicuous scar formation, there were no instances of permanent functional damage to the eyelids. The age of the patients varied between 19 and 46 years (mean 29 years, median 28 years). Two of them complained of weight loss and 
lassitude (patients 3 and 6). Patient 6 reported a history of right facial palsy and a vesicular eruption of the right ear one year ago, most probably a Ramsay Hunt syndrome, due to herpes zoster of the geniculate ganglion. Patient 7 reported an episode of thoracic herpes zoster in August 1984. The other patients declared themselves to be in good general health; they had no clinical evidence of malignant disease and none of them had recently been in hospital.

The healing period of the ocular involvement in these 19 patients varied between three weeks and five months (median one month). Eight out of $19(42 \%)$ still felt some pain in the orbital region, though the skin and eye lesions had cleared.

\section{SEROLOGICAL RESULTS}

All these patients with $\mathrm{HZO}$ had antibodies against HTLV-III $(100 \%)$. In the control group only seven out of 57 patients were seropositive (12-2\%). Fisher's exact test: $p=0 \cdot 001$.

\section{OPHTHALMOLOGICAL FINDINGS}

Table 1 summarises the ophthalmological findings in these 19 patients. The corneal complications were described in accordance with the terminology used by Liesegang. ${ }^{4}$ Seventeen patients $(89.4 \%)$ showed some form of corneal involvement, ranging in severity from a mild punctate epithelial keratitis to a vision-threatening corneal oedema. Only the two patients with predominant involvement of the maxillary nerve did not have corneal complications.
Uveitis was seen in 10 out of 19 patients $(52.6 \%)$, with posterior synechiae in three of them.

Eleven of the 19 patients $(57 \cdot 8 \%)$ suffered from a decrease in visual acuity attributable to the sequelae of their zoster infection. In six patients (cases 8, 9, $11,15,16$, and 17) there was a drop in visual acuity due to the formation of central nummular corneal scars. Two patients (cases 1 and 10) developed a serpiginous ulceration which resulted in corneal thinning and irregular astigmatism and a more pronounced decrease in visual acuity. Patient 3 had peripheral neovascularisation of the cornea, central nummular scars, and some degree of corneal oedema. The visual acuity of patient 4 was reduced to $6 / 60$ as a result of chronic corneal oedema. This patient had a prolonged illness and suffered from keratouveitis and endotheliitis. After seven weeks of illness he was treated with intravenous acyclovir 30 $\mathrm{mg} / \mathrm{kg}$ for seven days, with improvement of his clinical state. Vasculitis with anterior segment ischaemia led to a thickened oedematous cornea and a white limbus surrounded by dilated vessels, much as is seen after an extensive corneal burn. This was the only patient treated with intravenous acyclovir. All other patients received a combination of cycloplegic drugs (atropine 1\%) and oxytetracycline 1\% and hydrocortisone $0.5 \%$ ointment. The atropine was prescribed twice daily until flare and cells had completely disappeared. The ointment was prescribed from twice to six times daily depending on the severity of the ocular involvement, and it was continued until the eye became white.

Table 1 Ocular complications in 19 patients with $\mathrm{HZO}$

\begin{tabular}{|c|c|c|c|c|c|c|}
\hline No. & Age & Sex & $V A$ & Ocular involvement & Duration & Sequelae \\
\hline 1 & 33 & $\mathbf{M}$ & $6 / 15$ & EP, ASI, SU, uveitis & $5 \mathrm{M}$ & Peripheral+central NCS, astigmatism \\
\hline 2 & 26 & $\mathbf{M}$ & $6 / 6$ & EP, ASI & $5 \mathrm{M}$ & Peripheral NCS \\
\hline 3 & 32 & $\mathbf{M}$ & $6 / 15$ & EP, ASI & $3 \mathbf{M}$ & $\begin{array}{l}\text { Central + peripheral NCS, neovascularisation } \\
\text { Deep interstitial oedema }\end{array}$ \\
\hline 4 & 34 & $\mathbf{M}$ & $6 / 60$ & EP, ASI, keratouveitis, endotheliitis & $2 \mathbf{M}$ & Chronic corneal oedema, posterior synechia \\
\hline 5 & 27 & $\mathbf{M}$ & $6 / 6$ & EP, uveitis & $6 W$ & None \\
\hline 6 & 29 & $\mathbf{M}$ & $6 / 6$ & EP, ASI & $1 \mathrm{M}$ & Peripheral NCS \\
\hline 7 & 36 & $\mathbf{M}$ & $6 / 7 \cdot 5$ & EP, ASI & $3 W$ & Peripheral NCS \\
\hline 8 & 20 & $\mathbf{M}$ & $6 / 10$ & Central ASI, uveitis & $1 \mathrm{M}$ & Central NCS \\
\hline 9 & 34 & $\mathbf{M}$ & $6 / 8 \cdot 6$ & ASI, uveitis & $1 \mathrm{M}$ & Central+ peripheral NCS \\
\hline 10 & 25 & $\mathbf{M}$ & $6 / 15$ & EP,SU, uveitis & $2 \mathbf{M}$ & $\begin{array}{l}\text { Corneal thinning, neovascularisation, } \\
\text { Astigmatism, posterior synechia }\end{array}$ \\
\hline 11 & 19 & $\mathbf{F}$ & $6 / 12$ & PEK, ASI, uveitis & $1 \mathrm{M}$ & Central+peripheral NCS, posterior synechiae \\
\hline 12 & 28 & $\mathbf{M}$ & $6 / 6$ & None & $3 W$ & None \\
\hline 13 & 24 & $\mathbf{F}$ & $6 / 6$ & EP, PEK, uveitis & $3 W$ & Peripheral NCS \\
\hline 14 & 25 & $\mathbf{F}$ & $6 / 6$ & PEK & $1 \mathrm{M}$ & None \\
\hline 15 & 25 & $\mathbf{M}$ & $6 / 12$ & ASI, uveitis & $6 W$ & Central+peripheral NCS \\
\hline 16 & 46 & $\mathbf{M}$ & $6 / 15$ & EP, PEK & $1 \mathrm{M}$ & Central NCS \\
\hline 17 & 22 & $\mathbf{M}$ & $6 / 10$ & ASI, uveitis & $1 \mathbf{M}$ & Central+peripheral NCS \\
\hline 18 & 31 & $\mathbf{F}$ & $6 / 6$ & ASI & $3 W$ & None \\
\hline 19 & 34 & $\mathbf{M}$ & $6 / 6$ & None & $3 W$ & None \\
\hline
\end{tabular}

$\mathrm{VA}=$ visual acuity. Duration: $\mathrm{M}=$ months, $\mathrm{W}=$ weeks. $\mathrm{EP}=$ early pseudodendrites. $\mathrm{PEK}=$ punctate epithelial keratitis. $\mathrm{ASI}=$ anterior stromal infiltrates. $\mathrm{SU}=$ serpiginous ulceration. $\mathrm{NCS}=$ nummular corneal scars. 
Fundus lesions which we considered to be unrelated to the actual attack of herpes zoster were observed in six patients. The fundus of the right eye (contralateral to the herpes zoster infection) of patient 2 showed a heavy perivasculitis of the peripheral vessels and a moderate degree of vitreous flare. Five other patients (cases 6,11,13,17, and 18) had bilateral perivasculitis of the peripheral retinal vessels, varying from a discrete perivascular sheathing to a frank perivascular infiltrate.

\section{Discussion}

The most striking finding in this study is that all our patients with HZO are HTLV-III seropositive. This statistically highly significant association amply confirms our clinical impression that there is a relationship between the rising number of cases of $\mathrm{HZO}$ and the advent of HTLV-III infections in Rwanda. As already suggested by Cole and coworkers, ${ }^{5}$ acquired immune deficiency syndrome (AIDS) should be considered in young, healthy persons with $\mathrm{HZO}$ and no known cause of immunosuppression. They described HZO in four patients, two with AIDS and two with the AIDS related complex. Our series of HZO adds an important aspect to their observation: HZO is not only a manifestation seen in patients with AIDS or AIDS-related complex, but also a marker for HTLV-III seropositivity in healthy carriers. Indeed 17 of 19 seropositive patients with HZO $(89.4 \%)$ affirmed themselves to be in good health. They had no lymphadenopathy and they did not complain of weight loss, fatigue, night sweats, or diarrhoea. The clinical features of herpes zoster ophthalmicus in HTLV-III positive patients are somewhat different from the classical picture of this disease. In our opinion two distinct differences should be stressed. First, the peak incidence of HTLV-III related HZO is situated in a young age group (third decade), and, secondly, the disease tends to run a more severe course in HTLV-III positive patients in terms of corneal involvement and postzonal pain. Table 2 illustrates these differences by comparing selected clinical features of our

Table 2 Comparison of selected clinical features in two groups of patients with $\mathrm{HZO}$

\begin{tabular}{lll}
\hline & Ourseries & $\begin{array}{l}\text { Womack and } \\
\text { Liesegang }^{6}\end{array}$ \\
\hline Number of patients & 19 & 86 \\
Mean age & 28 years & 65 years \\
Ocular involvement & $17(89 \cdot 4 \%)$ & $61(70 \cdot 9 \%)$ \\
Corneal involvement & $17(89 \cdot 4 \%)$ & $47(54 \cdot 6 \%)$ \\
Uveitis & $10(52 \cdot 6 \%)$ & $37(43 \%)$ \\
Substantial visual loss (6/15 or less) & $5(26 \cdot 3 \%)$ & $24(28 \%)$ \\
Postherpetic neuralgia & $8(42 \%)$ & $15(17 \cdot 4 \%)$ \\
\hline
\end{tabular}

patients with a series published by Womack and Liesegang. ${ }^{6}$ The rates of corneal involvement and of postherpetic neuralgia are much higher in our series of HTLV-III seropositive patients. Similar conclusions are reached by Sandor and coworkers, ${ }^{7}$ who state that $\mathrm{HZO}$ occurs with frequent ocular complications in a subgroup of adults distinguishable by their young age and the presence of AIDS-risk factors.

We believe from the present study that the laboratory investigation of patients with herpes zoster should include a determination of antibodies against HTLV-III in areas where this virus is endemic or in patients with known risk factors. The presence of a perivasculitis or perivascular sheathing of the peripheral fundus vessels in both eyes may already give a clue to the presence of HTLV-III infection in a case of HZO. We described this finding in patients with AIDS and AIDS-related complex, both in children and in adults, ${ }^{89}$ and observed it in five patients of the present series. The ophthalmologist should inform the seropositive patient that he is a potential source of infection for his sexual partners and refer him to a venereologist for further counselling on this subject.

The high percentage of corneal involvement with subsequent visual loss and of postzonal neuralgia in this group of patients seems to justify the routine use of intravenous acyclovir, the current treatment of choice for zoster infections in immunocompromised patients. ${ }^{10}$ Unfortunately this treatment is far too expensive for routine use in a developing country. In our patients we were reluctant to give large doses of steroids for several reasons. Systemic treatment with steroids, advocated for severe cases of $\mathrm{HZO}$ and postherpetic neuralgia, ${ }^{112}$ is in our opinion contraindicated in HTLV-III seropositive patients, especially in Africa, where follow-up is less than optimal and where complications of systemic steroid treatment may cause more harm than the loss of visual acuity in one eye. Topical prednisone treatment should be used sparingly in the presence of epithelial disease, ${ }^{4}$ and a high number of our HTLVIII seropositive patients presented with early pseudodendrites and punctate epithelial keratitis (see Table 1 ), indicating active viral replication with the corneal epithelium. Although we agree that the visual outcome in some of our cases was negatively influenced by the withholding of potent topical steroids, it should be kept in mind that, once instituted, steroids need to be given over a long period, as later recrudescences are especially common after corticosteroid withdrawal. This means placing a heavy financial burden on our mostly poor patients.

Further follow-up of our HTLV-III seropositive patients with $\mathrm{HZO}$ but in good general health will tell whether they are at greater risk for developing AIDS 
or the AIDS-related complex than a seropositive group without a history of herpes zoster.

Addendum. In the period between March 1986 and September 1986 we diagnosed 21 new cases of HZO at our ophthalmology department. All but one patient had antibodies against HTLV-III. The one seronegative patient was a 55-year-old expatriate.

\section{References}

1 Weller TH. Varicella and herpes zoster: changing concepts of the natural history, control, and importance of a not-so-benign virus. N Engl J Med 1983; 309: 1362-8, 1434-40.

2 Van de Perre P, Rouvroy D, Lepage P, et al. Acquired immunodeficiency syndrome in Rwanda. Lancet 1984; ii: 62-5.

3 Sandstrom EG, Schooley RT, Ho DD, et al. Detection of human anti-HTLV-III antibodies by indirect immunofluorescence using fixed cells. Transfusion 1985; 25: 308-12.

4 Liesegang TJ. Corneal complications from herpes zoster ophthalmicus. Ophthalmology 1985; 92: 316-24.

5 Cole EL, Meisler DM, Calabrese LH, Holland GN, Mondino BJ, Conant MA. Herpes zoster ophthalmicus and acquired immune deficiency syndrome. Arch Ophthalmol 1984; 102: 1027-9.

6 Womack LW, Liesegang TJ. Complications of herpes zoster ophthalmicus. Arch Ophthalmol 1983; 101: 42-5.

7 Sandor EV, Millman A, Croxson TS, Mildvan D. Herpes zoster ophthalmicus in patients at risk for the acquired immune deficiency syndrome (AIDS). Am J Ophthalmol 1986; 101: 153-5.

8 Kestelyn P, Van de Perre P, Rouvroy D, et al. A prospective study of the ophthalmologic findings in the acquired immune deficiency syndrome in Africa. Am J Ophthalmol 1985; 100: 230-8.

9 Kestelyn P, Lepage P, Van de Perre P. Perivasculitis of the retinal vessels as an important sign in children with AIDS-related complex. Am J Ophthalmol 1985; 100: 614-5.

10 Shepp DH, Dandliker PS, Meyers JD. Treatment of varicellazoster virus infection in severely immunocompromised patients: a randomized comparison of acyclovir and vidarabine. $N$ Engl J Med 1986; 314: 208-12.

11 Elliot FA. Treatment of herpes zoster with high doses of prednisone. Lancet 1964; ii: $610-1$.

12 Eaglstein WH, Katz R, Brown JA. The effects of early corticosteroid therapy on the skin eruption and pain of herpes zoster. JAMA 1970; 211: 1681-3.

Accepted for publication 28 October 1986. 